\title{
Paisajes del viñedo, turismo y sostenibilidad: interrelaciones teóricas y aplicadas
}

\author{
Vineyard landscapes, tourism, and sustainability: \\ theoretical and applied interrelationships
}

\author{
M. Carmen Cañizares Ruiz ${ }^{1 *}$ (1) \\ Ángel Raúl Ruiz Pulpón ${ }^{2}$
}

\section{Resumen}

Los paisajes del viñedo, como paisajes culturales agrarios, aportan gran potencial para impulsar diversas fórmulas de turismo sostenible, entendido como aquél que vela por un equilibrio entre los condicionantes ambientales, sociales y económicos que rodean a dicha actividad. En estos paisajes se define el estado de conservación de los recursos naturales, se expresa la autenticidad sociocultural de las comunidades locales y se favorece el mantenimiento de las actividades económicas, bien a partir de su propia finalidad productiva, bien como recurso cultural y escénico en base a su viabilidad turística. Partimos, en este caso, de distintas aproximaciones teóricas que revelan la importancia de estos paisajes en relación con el territorio entendido como patrimonio, con la filosofía de la sostenibilidad y con su atractivo turístico a partir de los beneficios que aportan al visitante. Desde un punto de vista aplicado, consideramos que las explotaciones vitivinícolas certificadas con Denominación de Origen propia, comúnmente conocidas como "Vinos de Pago", presentan una importante potencialidad para planificar y promover fórmulas de turismo sostenible.

Palabras clave: Paisajes del viñedo; patrimonio agrario; turismo sostenible; servicios ecosistémicos culturales; Pagos Vitivinícolas.

\begin{abstract}
Vineyard landscapes, as agricultural cultural landscapes, bring great potential to promote formulas of sustainable tourism, understood as striving for a balance between the environmental, social, and economic conditions surrounding this activity. These landscapes define the state of conservation of natural resources, express the sociocultural authenticity of local communities, and encourage the maintenance of economic activities (either from their own productive purpose, or as cultural and scenic resource based on tourist viability). In this paper, we deal with different theoretical approaches that reveal the importance of these landscapes in relation to the territory understood as heritage, with the philosophy of sustainability and with tourist attraction based on the benefits they bring to visitors. From an applied perspective, we consider that wine farms, certified as 'Wine Estates', have a significant potential to plan and promote sustainable tourism formulas.
\end{abstract}

Keywords: vineyard landscapes; agrarian heritage; sustainable tourism; cultural ecosystemics services; wines estate.

\footnotetext{
1 Departamento de Geografía y Ordenación del Territorio. Universidad de Castilla-La Mancha (España). MCarmen.Canizares@uclm.es

* Autora para correspondencia

2 Departamento de Geografía y Ordenación del Territorio. Universidad de Castilla-La Mancha (España). Angelraul.ruiz@uclm.es 


\section{Introducción}

La revalorización de los atractivos naturales, culturales, y patrimoniales de los espacios rurales es uno de los fenómenos más relevantes del nuevo escenario de relaciones entre áreas rurales y urbanas de las últimas décadas (Kayser, 1990; Short, 2006; Bell, 2006). Una percepción en la que conceptos como cultura, patrimonio, paisaje y sostenibilidad adquieren una nueva dimensión. Consideramos que el término paisaje agrupa y dota de nuevos significados a todos ellos, puesto que ejemplifica la interacción de los factores naturales y/o humanos en un espacio definido, según los reconocidos preceptos del Convenio Europeo del Paisaje (Consejo de Europa [CE], 2000). Esta capacidad de integración de los elementos bióticos y abióticos sitúa al paisaje como síntesis de aspectos culturales, ecológicos, medioambientales y sociales de todos los territorios y, en particular, de los rurales, convirtiéndose en un factor muy favorable para el desarrollo de diferentes actividades, entre las cuales se encuentra la práctica del turismo.

Cuando el turismo lo asociamos al disfrute del paisaje, lo solemos identificar con tipologías de naturaleza, ecoturismo y/o turismo rural realizándose, preferentemente, en áreas naturales protegidas o de elevado interés estético. Actualmente, este tipo de actividades amplían su campo de acción a todo tipo de paisajes, incorporando los atractivos culturales y patrimoniales como factores de atracción. En este sentido, se constata un creciente interés por los paisajes de los espacios rurales que se entienden como expresiones de estructuras espaciales, geográficas, naturales, históricas, ecológicas, económicas, sociales y culturales; reflejan la influencia de una cultura en un espacio a lo largo del tiempo y se convierten, incluso, en expresiones morales de la relación entre un grupo humano y el territorio, en memoria del trabajo y en identidad. Su correcta interpretación debe realizarse no solo en clave económica (productividad aportada por las actividades agropecuarias), sino también, como lugares donde la sociedad postindustrial puede disfrutar de otros recursos recientemente revalorizados e identificados con el mundo rural, como la tranquilidad, el valor estético, la gastronomía, etc., que resultan imprescindibles para articular nuevas experiencias turísticas. Una respuesta lógica ante el creciente interés por la conservación ambiental y el protagonismo de lo patrimonial.

Los valores culturales de estos territorios a partir de su viabilidad turística generan respuestas emotivas y estéticas en torno a un determinado tipo de organización territorial, de paisajes y de tradiciones propias (Rosenberg y Walsh, 1997; Ruiz Urrestarazu, 2001). Como consecuencia, los paisajes de tradición agropecuaria (agrícolas, ganaderos, forestales,...) revelan la identidad de quienes los habitan y en su configuración, las personas vinculadas con ellos ven reflejada su propia identidad. Muchos de estos lugares ya están reconocidos como Paisajes Culturales en la Lista del Patrimonio Mundial de la UNESCO al cumplir una serie de requisitos basados en su representatividad institucional, histórica, social, y estética.

Entre todos ellos, los asociados al viñedo son algunos de los que mejor ejemplifican esa estrecha relación entre hombre y medio, contando con un fuerte carácter cultural. Un paisaje humanizado en el que la revalorización de la cultura territorial ha calado de forma importante en todo aquello que se vincula con el patrimonio (Pillet, 2008). Su naturaleza es, por tanto, dinámica, consecuencia de los procesos sociales y económicos que ha ido incorporando en cada momento; y compleja, porque la integran componentes naturales y antrópicos (Ruiz Pulpón y Cañizares, 2017). Su impronta "no se plasma únicamente en la fisonomía del terreno: contribuye también a definir el carácter de las gentes que lo habitan, que se aprovechan de los recursos que ofrece, que lo viven, en definitiva" (Elías, 2016, p. 8). Hablamos, entonces, de grupos sociales que los perciben de una manera singular, representados por un importante compendio de elementos materiales e inmateriales que forma parte de su legado para la próxima generación. Esta naturaleza cultural se complementa, pues, con su función económica, lo que supone un factor estratégico para el desarrollo territorial.

Desde la óptica de contemplar el paisaje como recurso, en este caso el paisaje del viñedo en un territorio determinado, podemos avanzar hacia sus posibilidades como producto turístico capaz de sostener una actividad basada en los múltiples elementos que los caracterizan. Su dimensión geográfica se traduce en "un recurso turístico tanto con rasgos medioambientales como culturales para el que se generan unas potencialidades en la cualificación del espacio turístico" (Hernández, González y Ramón, 2017, p. 327). Nos referimos al propio cultivo de la vid, en primer lugar, a los vinos como acompañantes de una singular gastronomía, a sus elementos constructivos, a las fiestas relacionadas con el vino o a los rituales, como los asociados con la vendimia, todos ellos con gran potencialidad turística. En este contexto, ha cobrado especial interés el "enoturismo", modalidad que, en diversas regiones vitivinícolas, integra la gastronomía, la cultura, la arquitectura, el arte, el ocio, el contacto con la naturaleza, la salud y la calidad de vida.

La interconexión entre naturaleza, saber hacer y actividad económica permite plantear, como hipótesis inicial, que el turismo basado en el disfrute de los paisajes del viñedo es, de manera general, una 
actividad claramente sostenible, dado su arraigo territorial y los beneficios que supone en visitantes y responsables de explotación. Evidentemente, la conjunción de estos criterios ambientales, sociales y económicos no siempre se realiza de la manera más efectiva. En un contexto donde la agricultura de mercado sigue siendo hegemónica, a veces es difícil articular iniciativas de diversificación económica que respondan fielmente al paradigma de la sostenibilidad, ofreciendo o bien productos turísticos despersonalizados, o bien, experiencias que no guardan el debido respeto a las tradiciones, a los rituales o a los paisajes consecuencia de su creciente comprensión como Commodity (Crouch, 2006).

El objetivo, en este caso, es determinar cómo los paisajes del viñedo, entendidos como uno de los múltiples recursos al servicio de la actividad turística, aportan potencial para impulsar formas de turismo sostenible al presuponer un equilibrio entre los condicionantes ambientales, económicos y sociales que participan en el territorio. A continuación, el desarrollo teórico se centrará en el análisis de la relación entre paisajes del viñedo/turismo sostenible, mientras que la aplicación práctica se centra en dos espacios seleccionados, representativos de los Pagos Vitivinícolas en España.

\section{Metodología}

La metodología de estudio se articula en dos fases diferenciadas: la primera, de tipo teórico, se basa en el empleo de fuentes que permiten entender la patrimonialización de los paisajes rurales y, de manera concreta, de los viñedos en base a la documentación institucional y científica existente a distintas escalas. En ella se caracterizará el turismo bajo el enfoque de la sostenibilidad, definiendo las claves que permiten aunar ambos aspectos, principalmente relacionadas con la valorización del patrimonio agrario y la existencia de Servicios Ecosistémicos Culturales (SEC) asociados a los paisajes del viñedo. La segunda fase, de tipo aplicado, permite analizar el nivel de adecuación a estos principios a partir de estudios de caso llevados a cabo en dos explotaciones, Pagos Vitivinícolas, que poseen la certificación "Vino de Pago" en España, cuyos resultados podrían hacerse extensibles a todos los territorios que cuentan con esta certificación.

\subsection{Primera fase: aproximación teórica}

Abordar el proceso de patrimonialización de determinados paisajes, como es el caso de algunos viñedos, nos remite al protagonismo que el concepto de paisaje ha ido adquiriendo después de la firma del Convenio Europeo del Paisaje (CE, 2000), en relación directa con la importancia del propio territorio en los ámbitos científico, político y social. La reivindicación de su carácter cultural al incluir un conjunto de recursos heredados que son reflejo de los valores, creencias y tradiciones en continua evolución permite constatar que "el paisaje se ha acercado al "nuevo paradigma del patrimonio" (Silva y Fernández, 2017, p. 129 y ss.). En este contexto, como han analizado algunos geógrafos, la patrimonialización no es sino la consecuencia lógica del descubrimiento de sus valores para las poblaciones que los habitan y viven de diversas formas y, en ocasiones, incluso para toda la Humanidad (Sanz, 2012). En ella intervienen procesos de apropiación social y de asignación de valores por parte de la sociedad local, de "abajo-arriba", por ejemplo conservando las tradiciones y el folclore, y/o a través de las instituciones, de "arriba-abajo" mediante su inventario, catalogación y protección, principalmente (Silva y Fernández, 2017; Molinero, 2016).

En el ámbito institucional internacional algunos paisajes del viñedo son catalogados como Paisajes Culturales por la Unesco e incluidos en la Lista del Patrimonio Mundial como Cinque Terre en Italia o la Jurisdicción de Saint Emilion en Francia, entre otros, lo cual les confiere un reconocimiento por su excepcional valor universal. En España, el Plan Nacional Paisaje Cultural aprobado en 2012 para salvaguardar los paisajes españoles con valores culturales como parte de la política de patrimonio, aporta un enfoque novedoso, por cuanto no se restringe a los paisajes de excepcional valor, siguiendo el Convenio Europeo del Paisaje (Mata, 2016). Afronta una realidad "dinámica y compleja", de "difícil gestión" en la que contempla, también, su carácter holístico, la multidisciplinariedad, las diversas escalas del paisaje como hecho territorial, los agentes implicados, la vulnerabilidad del carácter del paisaje, los conflictos de propiedad y de uso, el escaso desarrollo de una legislación específica de paisaje, y la titularidad de los terrenos, preferentemente privada (Instituto del Patrimonio Cultural Español [IPCE], 2015) ${ }^{3}$.

3 El Plan Nacional de Paisaje Cultural incluye los siguientes paisajes del viñedo: los del Valle de Andaráx (Almería), Cangas de Nancea (Oviedo), los viñedos del Archipiélago Canario, las D.O. de Origen Jerez-Xeres-Sherry (Cádiz), Cariñena (Zaragoza), Toro (Zamora y Valladolid), Tierras de León (León), Ribera del Duero (Burgos, Valladolid, Segovia y Soria), Priorat (Tarragona), Utiel-Requena (Valencia), Ribera Sacra (Lugo), Rioja Alta (Logroño) y Rioja Alavesa (Álava), y en Castilla-La Mancha, las de La Mancha (Toledo, Ciudad Real, Cuenca y Albacete), Méntrida (Toledo) y Mondéjar (Guadalajara). 
Cabe citar, también, dos publicaciones relevantes para enmarcar esta temática: el Atlas del cultivo tradicional del viñedo y sus paisajes singulares (Elías, 2016) dedicado a documentar acciones, técnicas y tradiciones vinculadas al pasado y que han caracterizado estos paisajes singulares en áreas concretas que "por sus valores patrimoniales de paisaje y por las manifestaciones culturales que en él puedan encontrarse (...) deben ser catalogados y señalados con alguna forma de protección" (Elías, 2016, p. 27). Y la obra conjunta Paisajes Patrimoniales de España (Molinero, et al., 2018), cuyo Tomo II se dedica a los paisajes patrimoniales de dominante agraria donde se aborda el singular valor patrimonial de los paisajes vitícolas a través de ejemplos destacados: Ribeira Sacra, Penedés,...

En segundo lugar, para analizar el turismo en clave de sostenibilidad desde el ámbito teórico, partimos de las sucesivas definiciones de turismo sostenible lanzadas por la Organización Mundial del Turismo (OMT) haciendo referencia al respeto de la autenticidad sociocultural de las comunidades anfitrionas y a la conservación de sus valores y activos naturales, culturales, arquitectónicos y tradicionales para la consecución de un turismo sostenible. También de los últimos dictámenes relativos a esta temática a escala global como la Carta Mundial del Turismo Sostenible (2015) y las conclusiones del Año Internacional del Turismo Sostenible para el Desarrollo (2017) con la finalidad de identificar todos aquellos preceptos del turismo sostenible que se reproducen en los paisajes del viñedo en general. Junto con todo ello, como referencias científicas imprescindibles destacamos algunas obras como Análisis territorial del turismo y planificación de destinos turísticos (Vera, Palomeque, Gómez y Clavé, 2013), entre otras.

Las claves que permiten aunar paisajes del viñedo y turismo sostenible, las vinculamos, de manera concreta, con la valorización de su patrimonio agrario y con el aporte de Servicios Ecosistémicos Culturales (SEC) asociados a los paisajes del viñedo, elementos clave para acercar la actividad turística a la sostenibilidad. En el primer caso, es la Carta de Baeza para la protección del patrimonio agrario (Castillo, 2013) la que ofrece las pautas más claras a la hora de identificar e inventariar los elementos con valor patrimonial en los viñedos, de cara a revalorizar los bienes materiales e inmateriales que deben ser respetados y conservados para garantizar su autenticidad, aspecto que también relacionamos con las propuestas de la OMT para el turismo sostenible. Principalmente, elementos materiales como utensilios, medios de transporte y documentos (bienes muebles), construcciones (inmuebles), e inmateriales como los culturales, lingüísticos, tradiciones y rituales que, con especificidades, podemos encontrar en cualquier territorio vitivinícola. En el segundo caso, los Servicios Ecosistémicos, definidos por Naciones Unidas en el Millenium Ecosystem Assessment (MEA, 2005) los vinculamos con la identificación de emociones y sentimientos que surgen de la contemplación de un paisaje, partiendo de la hipótesis de que cuanto mejor sea el estado de conservación, mejor será la percepción o experiencia por parte del visitante y/o de la población local. Ello nos conduce a la exposición de una serie de beneficios que la naturaleza transmite al ser humano (servicios ecosistémicos) que están estrechamente relacionados con los paisajes agrarios y, por tanto, con los del viñedo. En esta propuesta se reflexiona sobre los considerables beneficios que la transformación de los ecosistemas naturales ha supuesto para el bienestar humano y la necesidad de implementar medidas que fomenten y mantengan esta clase de servicios. Entre las contribuciones que realizan los ecosistemas se encuentran las de tipo "cultural" que, en este caso, nos parecen especialmente destacables por cuanto se vinculan con beneficios no materiales que promueven el enriquecimiento espiritual, el desarrollo cognitivo, la reflexión, y la experiencia estética y recreativa, todos de posible aplicación a partir de la revalorización patrimonial y el desarrollo del turismo (MEA, 2005). Insistimos que la percepción positiva de los paisajes se establece en base a su conservación, criterio esencial para la OMT en el tratamiento de la relación turismo/sostenibilidad.

\subsection{Segunda fase: aproximación práctica}

Una vez establecidas las relaciones entre el paisaje del viñedo y el turismo sostenible, se realiza una aproximación a diversas experiencias de enoturismo en España con el objetivo de analizar, dentro de unos parámetros generales, el nivel de adecuación e interrelación de la oferta turística respecto a los principios de sostenibilidad y patrimonialización analizados en el apartado teórico. Este acercamiento práctico se ha realizado a partir del estudio de diversos casos relevantes, en los que se ha seguido una serie de pautas metodológicas básicas: la primera, la selección de la escala territorial apropiada; la segunda, la justificación de los estudios de caso planteados; y la tercera, los criterios con los que pretendemos evaluar el nivel de adecuación de la oferta enoturística a los principios de la sostenibilidad. 
En primer lugar, y respecto a la escala territorial de estudio, distinguimos como las certificaciones territoriales, en este caso, las Denominaciones de Origen (DO) o Denominaciones de Origen Protegidas (DOP), pueden erigirse como las principales unidades espaciales de análisis, ya que en su constitución juegan un papel esencial los factores geográficos que, en definitiva, son los que confieren la calidad y la particularidad a los vinos producidos. Dado que la experiencia enoturística se desarrolla y se optimiza en el contexto de una visita a una bodega, consideramos que las Denominaciones de Origen propias, comúnmente conocidas como Pagos Vitivinícolas, pueden ser la escala territorial más idónea para descubrir prácticas de turismo sostenible. Esta idoneidad se interpreta por la estrecha relación existente entre la calidad de los vinos elaborados y el territorio donde se producen, ya que el terroir o paraje ofrece una serie de peculiaridades ambientales y culturales que condicionan la exclusividad del producto final. Las singularidades de los Pagos Vitivinícolas suponen un elemento de atracción turística puesto que ejemplifican el arraigo territorial, se basan en el empleo de unos métodos de producción específicos, y despiertan interés ante las exigencias en diseño, etiquetado y crítica especializada indispensables para su reconocimiento en esta figura de calidad, la de mayor prestigio dentro de las certificaciones territoriales asociadas al vino (Ruiz Pulpón, 2013; Ruíz Pulpón y Plaza, 2015, p. 57). Aparte de estos atractivos, encontramos otros criterios de tipo ambiental, cultural y comercial que pueden ser considerados muy relevantes a la hora de diseñar estrategias de turismo sostenible. En concreto, podemos destacar los requisitos culturales, puesto que se debe evaluar la repercusión de la bodega en el entorno cultural más inmediato, especialmente el papel que puede desempeñar en la sociedad local, así como al incentivar métodos de producción específicos que fueran testimonio de saberes tradicionales. Por tanto, se establece una estrecha vinculación entre singularidad productiva y comunidad local, precepto definido por la OMT para el turismo sostenible y que, además, juega un papel clave en la interpretación de la identidad territorial.

En segundo lugar, del total de veintidós certificaciones actuales de Vinos de Pago en España, hemos elegido dos a modo de ejemplos que, en principio, responden a los planteamientos ambientales y socioculturales que la OMT recomienda como baluartes de la sostenibilidad turística. Desde el punto de vista de los valores ambientales, se ha escogido el Pago Dehesa del Carrizal, localizado en la parte norte de la provincia de Ciudad Real (Castilla-La Mancha), concretamente en el entorno del Parque Nacional de Cabañeros, aspecto que complementa su orientación y/o identificación de la oferta turística de los propios viñedos y de la bodega. Desde el punto de vista sociocultural, se ha seleccionado el Pago Los Balagueses, ubicado en la Comunidad Valenciana, dentro del área de acción de la Denominación de Origen Utiel-Requena. Su justificación reside en la importante dimensión histórica del cultivo en esta comarca, con una tradición vitivinícola de más de 2.000 años, lo que sin duda supone un factor esencial a la hora de comprender las interacciones entre los usos agrarios del territorio y la identidad sociocultural de las comunidades locales.

Tabla 1. Principales ámbitos temáticos del cuestionario

\begin{tabular}{|c|l|}
\hline Ámbito & \multicolumn{1}{c|}{ Cuestiones relativas a: } \\
\hline Sociocultural & $\begin{array}{l}\text { Tradición del viñedo en la comarca } \\
\text { Respeto por la autenticidad sociocultural } \\
\text { Percepción de la población local sobre el sello de calidad } \\
\text { Información sobre el proceso de elaboración } \\
\text { Oferta de actividades culturales } \\
\text { Elementos representativos del patrimonio natural y cultural }\end{array}$ \\
\hline \multirow{5}{*}{ Económica } & $\begin{array}{l}\text { Viabilidad futura de la oferta de enoturismo } \\
\text { Papel en la diversificación de rentas } \\
\text { Valoración del visitante sobre la certificación conseguida } \\
\text { Posibilidad de ampliación de la oferta turística } \\
\text { Personas cualificadas en enoturismo } \\
\text { Compra de productos en bodega }\end{array}$ \\
\hline & $\begin{array}{l}\text { Valoración del paisaje como parte integrante de la experiencia } \\
\text { Información sobre el papel de los condicionantes geográficos } \\
\text { Mantenimiento de procesos ecológicos esenciales } \\
\text { Producción de vino ecológico } \\
\text { Relevancia de la conservación del viñedo tradicional } \\
\text { Beneficios de la contemplación del paisaje del viñedo }\end{array}$ \\
\hline
\end{tabular}

Elaboración propia 
En tercer lugar, para tratar de enjuiciar el nivel de sostenibilidad de la oferta turística de cada uno de los Pagos, se han efectuado diversas entrevistas a los responsables de las explotaciones. En el diseño del cuestionario se han tenido en cuenta los parámetros que establece la OMT para definir el turismo sostenible: la dimensión ambiental, especialmente vinculada con la conservación de los recursos naturales; la dimensión sociocultural, entendida como el respeto por las tradiciones y la preservación de la autenticidad; y la dimensión económica, valorando la diversificación de rentas en la explotación (Tabla 1).

El resultado es un cuestionario de naturaleza integral que responde a la necesidad de contar con un primer diagnóstico, en clave de sostenibilidad, de la oferta turística de este tipo de explotaciones, considerando que puede ser enriquecido por otras aproximaciones más ambiciosas que apuesten o bien por una mayor diversidad en el tamaño de la muestra, por ejemplo haciéndola extensiva a todos los Pagos Vitivinícolas certificados en España; o bien por el diseño de un sistema de indicadores que permita evaluar la sostenibilidad turística. Seguidamente, en la discusión de resultados, se valorará la correspondencia existente entre los aspectos patrimoniales y la valorización de los paisajes del viñedo, junto con la aplicación de los principios del turismo sostenible asociados a la oferta turística (enoturística) de los Pagos.

\section{Resultados}

Para ordenar los resultados de la investigación, partimos de la interrelación de aspectos teóricos en torno a los paisajes del viñedo, turismo y sostenibilidad, para después, analizar los estudios de caso planteados.

\subsection{Interrelaciones teóricas: dimensión patrimonial y correcta valorización de los paisajes del viñedo}

Los paisajes, como partes individualizadas del territorio en función de sus características naturales y/o culturales, pueden ser valorados como patrimonio al personificar la identidad sociocultural de las poblaciones locales. Los paisajes de la agricultura son claramente representativos de esta naturaleza patrimonial, ya que surgen de la idea de pertenencia colectiva, del reconocimiento social de los valores materiales y culturales, y de la preocupación ciudadana por conservarlos y transmitirlos (Silva, 2009). Sin olvidar que su finalidad sigue siendo claramente productiva y que el escenario actual de liberalización de los mercados agrarios es poco propicio a su reconocimiento cultural, urge el planteamiento de políticas integrales que velen por la compatibilidad de ambas actividades, tanto económicas como sociales, que posibiliten el mantenimiento de la diversidad cultural, natural y paisajística de Europa según lo que ya contempló, en su momento, la Estrategia Territorial Europea (Comisión Europea [CE], 1999), o las recomendaciones de la Organización de Naciones Unidas (ONU) para el Año Internacional del Turismo Sostenible para el Desarrollo (Organización Mundial del Turismo [OMT], 2017a).

Cuando hablamos de patrimonio agrario consideramos la actividad desarrollada en el medio rural (cultivo, ganadería, explotación forestal, etc.) en su integridad diacrónica y sincrónica, es decir, comprendida a partir de la incorporación de los sucesivos avances científicos y técnicos, de la influencia de las disposiciones administrativas o de las diferentes formas de organización del trabajo, sin enjuiciarlas en términos de idoneidad o de eficiencia socioeconómica actual. De esta forma, nos referimos, por tanto, al legado relacionado con la herencia histórica de sus explotaciones (áreas de cultivo, dehesas, plantaciones forestales), bien sea de carácter material (paisajes, edificios relacionados con la producción y la trasformación de los productos, equipamientos agrarios, tipos de hábitat rural), bien etnográfico (oficios, artesanías, folklore) (Silva, 2008); sin obviar los bienes inmateriales, vinculados con la transmisión de saberes, de tradiciones y de rituales que, relacionados con la territorialidad y con la identidad, son capaces de generar diferentes emociones y sentimientos.

Según La Carta de Baeza sobre patrimonio agrario (Castillo, 2013), anteriormente citada, éste se encuentra "conformado por el conjunto de bienes naturales y culturales, materiales e inmateriales, generados o aprovechados por la actividad agraria a lo largo de la historia". En el caso de los viñedos, incluye elementos tangibles como utensilios, aperos o herramientas utilizadas en la labranza de la vid y en el almacenamiento y producción de vinos (prensas, tinajas, atrojes, pisadoras, estrujadoras,...); elementos vinculados con el transporte (tipos de carros, animales de tiro,...) y objetos bibliográficos que se concretan en la relación entre el viñedo y la literatura. Especial relevancia tienen los elementos constructivos que suelen presentar cierta singularidad en cada territorio (chozos, casas de labranza, corralizas, palomares, norias,...), así como las construcciones relacionadas con la transformación de la producción, en 
especial bodegas y alcoholeras, representativas tanto de procesos artesanales en forma de bodegas familiares unidas frecuentemente a las viviendas, como de la producción a gran escala en caso de las bodegas industriales; junto con el propio "paisaje del viñedo" (también denominado "paisaje del vino", "paisaje vitivinícola" o "paisajes vitícolas") en su condición de bien patrimonial, los asentamientos de población, y los caminos y vías pecuarias (cañadas, cordeles, veredas y coladas). Por su parte, el patrimonio agrario intangible abarca bienes como los términos singulares asociados a la cultura del vino, las creencias, los rituales y actos festivos, así como las numerosas fiestas locales asociadas con la religión o con las tradiciones como la vendimia. Otro conjunto de activos son los saberes, oficios y tradiciones agrarias, la gastronomía asociada en tiempos de recolección y también todos sus rituales. Finalmente, el patrimonio natural y genético (variedades locales de cultivos, razas autóctonas de animales, semillas, suelos, vegetación y animales silvestres asociados, etc.) completa esta diversidad y riqueza de elementos (bienes patrimoniales) con enorme potencialidad para su incorporación a la oferta turística.

A pesar de la diversidad de este tipo de activos, todos juegan un papel esencial en la construcción de la identidad territorial de las poblaciones locales y son expresión intrínseca de los valores fundamentales que las actividades agropecuarias trasfieren a la sociedad como su aportación a la alimentación, su relación armónica con el territorio basada en el binomio cultura-naturaleza, y su imprescindible contribución a la diversidad biológica y cultural (Cañizares y Ruiz, 2014). De este modo, su correcta valoración tanto en su vertiente material, como inmaterial, resulta necesaria a la hora de promover políticas que velen por la conservación y, que, en definitiva, definan esa autenticidad cultural que se pregona desde la OMT. La autenticidad sociocultural se convierte, por tanto, en una herramienta indiscutible para la sostenibilidad y también para la construcción de una verdadera identidad territorial. En principio, consideramos que todos los territorios tienen un stock de elementos patrimoniales —o capital patrimonializable —, pero para que este stock pueda cobrar valor patrimonial "debe pasar por un proceso de adaptación/transformación que asegure su capacidad para satisfacer una serie de necesidades y demandas contemporáneas" (Rubio, 2010, p. 138), por lo tanto, aunque los elementos patrimonializables existan previamente, los recursos patrimoniales se producen a posteriori y éstos podrán convertir los territorios en lugares turísticos si son aptos para dicho consumo (Almirón, Bertoncello y Troncoso, 2006).

\subsubsection{La sostenibilidad, exigencia de toda actividad turística}

A mediados de los años 90 del siglo XX, la OMT define el turismo como el conjunto de "actividades que realizan las personas durante sus viajes y estancias en lugares distintos al de su entorno habitual, por un período de tiempo consecutivo inferior a un año, con fines de ocio, por negocios y otros motivos" (OMT, 1994, p. 3). Actualmente, en la fase postfordista, es considerado como un fenómeno social, cultural y económico relacionado con los movimientos de las personas en el espacio que manifiesta un ritmo creciente y cuyo impacto económico es cada vez más relevante. Hoy el 10\% del Producto Interior Bruto mundial está relacionado con actividades turísticas y 1 de cada 10 empleos se vincula con ellas. Un subsector económico en continuo crecimiento pues, con datos de 2018, se contabilizan 1.326 millones de llegadas de turistas internacionales (el 57\% en Europa), 7\% más que el año anterior, 1,34 billones de \$ como ingresos generados por el turismo internacional (el 37\% en Europa), un 5\% más que el año anterior y, además, para 2019, la OMT prevé un aumento del 3-4 \% (OMT, 2019). Cifras que, con seguridad, se verán alteradas por las consecuencias de la grave crisis sanitaria mundial de 2020 .

Han sido clave algunos factores para explicar su evolución (turismo de élite, turismo de masas, turismo postfordista) e importancia en el momento actual, tales como la progresiva conquista del tiempo de ocio y, por tanto, la disponibilidad de la población para viajar, al menos en áreas desarrolladas. También, la conquista del espacio en aspectos como la movilidad, donde es evidente el avance, así como en el acceso a la información, junto con la disponibilidad de rentas y la capacidad de consumo turístico; aspectos a los que se añaden cuestiones sociológicas como la conversión de la vacación y el tiempo de ocio en necesidad básica relacionada con el bienestar personal (Vera, et al., 2013). Con todo ello, hoy el turismo, convertido en uno de los principales agentes de globalización, se practica atendiendo a diversas tipologías (urbano, rural, cultural, litoral,...), de las cuales aquí profundizaremos en el turismo en espacios rurales relacionado con el disfrute de los paisajes del viñedo.

Desde el ámbito geográfico nos interesa destacar cómo la actividad turística se fundamenta en la valoración social de determinados componentes geofísicos y geoculturales (Vera et al., 2013), es decir recursos 
y factores de atracción vinculados con los destinos turísticos principalmente, a los que prestaremos especial atención. Fundamentales son, también, las características del espacio emisor, las formas, las distancias y los flujos de viajes, junto con la morfología de los lugares de destino. Obviamente, son muchos los beneficios derivados, tanto en origen como en destino: aumento de rentas y de empleo en los lugares de destino, posibilidades de intercambio cultural y aprendizaje personal, planificación y conservación del patrimonio natural y cultural, etc. E igualmente, son muy conocidas algunas de sus consecuencias más negativas como su posible repercusión en la inflación, la salida de divisas, las alteraciones en la vida local de los destinos o la degradación ambiental por sobrexplotación de recursos naturales y culturales.

Este último aspecto nos permite enlazar con la sostenibilidad o, mejor dicho, con la "insostenibilidad" de muchas de las actividades turísticas. Calificada hoy como un proceso, un estilo de vida o una filosofía que nos acerca a una "moderación en el comportamiento de los individuos y los procesos sociales, en relación con el uso y disfrute de los recursos naturales" (Panadero, 2010), la sostenibilidad se ha convertido en exigencia ineludible de cualquier actividad económica dada la necesidad de minimizar la huella del hombre sobre el planeta. Claves en dicho proceso han sido: la aparición del concepto de "desarrollo sostenible" en el Informe Brutdland (1986) y I Cumbre de la Tierra celebrada en Río de Janeiro (1992) con la aprobación del Programa 21 (Agenda para el siglo XXI), del cual se deriva a su vez, en relación con el tema que aquí nos ocupa, la Agenda 21 para la industria de los viajes y del turismo (1996).

En el momento actual, después de cuatro Cumbres de la Tierra, la última celebrada de nuevo en Río de Janeiro (2012), la falta de acuerdo internacional y de consenso en cuestiones fundamentales, así como la lentitud en el avance por solucionar algunos problemas ambientales, nos enfrentamos a un futuro bastante complejo, agravado por la crisis actual. Precisamente el documento El futuro que queremos que surge de esta última cumbre, señala que "...el turismo bien concebido y bien gestionado puede hacer una contribución importante a las tres dimensiones del desarrollo sostenible, tiene estrechos vínculos con otros sectores y puede crear empleo decente y generar oportunidades" (Organización de Naciones Unidas, 2012, p. 39).

Nuevos planteamientos se han ido sucediendo (Cumbre del Milenio, Objetivos de Desarrollo del Milenio, Agenda Post-2015, Cumbre para el Desarrollo Sostenible, etc.) hasta llegar a la Agenda 2030 para el Desarrollo Sostenible y los consiguientes 17 Objetivos de Desarrollo Sostenible, entre los que, por cierto, no existe referencia expresa al turismo aunque, lógicamente, esta actividad tiene relación con algunos de ellos. De forma más directa con el Objetivo 8. Trabajo decente y crecimiento económico (creación de empleo), el Objetivo 12. Promoción y consumo responsables (consumo y producción sostenibles) y otros como los Objetivos 14 y 15, en relación con la vida submarina y la vida en los ecosistemas terrestres, respectivamente.

Cuando ponemos en relación el turismo, como actividad económica que incide en el desarrollo de los territorios, y las exigencias de sostenibilidad aplicables a cualquier tipo de actividad socioeconómica, precisamos que el turismo sea sostenible, es decir que atienda las necesidades de turistas y regiones, y proteja y fomente las oportunidades de empleo. A mediados de los años 90 del siglo pasado, la Carta Mundial del Turismo Sostenible (1995), firmada en Lanzarote (España), estableció 18 Principios para crear una estrategia turística mundial basada en el desarrollo sostenible. Y poco después, la ONU y la OMT, aprobaron el Código Ético Mundial para el Turismo (1999), en Santiago de Chile, con la finalidad de fomentar un turismo responsable y sostenible.

En España, un país donde, hasta ahora, el turismo ha generado un 12\% del Producto Interior Bruto y más del 12\% de empleo, las llegadas de turistas superaron los 81 millones en 2018, mientras que los ingresos casi alcanzan los 90 millones de $€$ (89.678 mill. €) (OMT, 2019). La Estrategia Española para el Desarrollo Sostenible (Ministerio de la Presidencia, 2007) consideró como objetivo principal para el futuro del turismo "revalorizar el sistema turístico en clave de sostenibilidad". Para ello "el crecimiento sostenible debe centrarse en el respeto de la capacidad de carga límite de los destinos, la reducción de los impactos negativos derivados del turismo, la preservación de los entornos sociales y culturales de los diferentes destinos turísticos y la puesta en valor del turismo sostenible" (Ministerio de la Presidencia, 2007, p. 53).

En 2015, la Cumbre Sustainable Tourism +20 celebrada en España, lanza la Carta Mundial del Turismo Sostenible, 20 años después de la carta anterior, realizando un llamamiento a la acción a todos los agentes implicados: Gobiernos y organizaciones internacionales; Destinos y comunidades locales; Industria del Turismo; Consumidores; Investigadores y formadores; Redes y ONGs. Poco después, 2017 se declara Año Internacional del Turismo Sostenible para el Desarrollo con el objetivo de apoyar un cambio en las políticas, 
en las prácticas de las empresas y en los comportamientos de los consumidores en favor de la sostenibilidad, con una atención especial a 5 áreas clave: 1. Crecimiento económico inclusivo y sostenible; 2. Inclusión social, empleo y reducción de la pobreza; 3. Uso eficiente de los recursos, protección ambiental y lucha contra el cambio climático; 4. Valores culturales, diversidad y patrimonio; y 5. Entendimiento mutuo, paz y seguridad. A la vez se desarrollan campañas como "Travel, Enjoy, Respect", orientadas a los consumidores y con gran repercusión social, cuya finalidad ha sido crear conciencia acerca del valor y la contribución que puede aportar el turismo sostenible al desarrollo (OMT, 2017b).

Recientemente, la OMT ha definido el turismo sostenible como "El turismo que tiene plenamente en cuenta las repercusiones actuales y futuras, económicas, sociales y medioambientales para satisfacer las necesidades de los visitantes, de la industria, del entorno y de las comunidades anfitrionas" (OMT, 2020). Algo transversal que debe aplicarse a todos los tipos de turismo y a todos los segmentos turísticos. Según este organismo (OMT, 2020), el Turismo Sostenible debe:

1) Dar un uso óptimo a los recursos medioambientales (...), manteniendo los procesos ecológicos esenciales y ayudando a conservar los recursos naturales y la diversidad biológica.

2) Respetar la autenticidad sociocultural de las comunidades anfitrionas, conservar sus activos culturales y arquitectónicos y sus valores tradicionales, y contribuir al entendimiento y la tolerancia intercultural.

3) Asegurar unas actividades económicas viables a largo plazo, que reporten a todos los agentes, unos beneficios socio-económicos bien distribuidos, (...) y que contribuyan a la reducción de la pobreza.

El desarrollo sostenible del turismo exige, además, la participación informada de todos los agentes relevantes, así como un liderazgo político firme para lograr una colaboración amplia y establecer un consenso. Un proceso continuo que requiere un seguimiento constante de sus incidencias, para introducir las medidas preventivas o correctivas que resulten necesarias, así como indicadores adecuados para proceder a la evaluación. También debe reportar un alto grado de satisfacción a los turistas y representar para ellos una experiencia significativa, que los haga más conscientes de los problemas y fomente en ellos unas prácticas turísticas sostenibles. Cuestiones que relacionaremos con los paisajes del viñedo en los que "la idea de desarrollo sostenible se ajusta bien a la acepción de herencia que es preciso conservar y mejorar para legar a las generaciones futuras, propia de todo patrimonio" (Porcal, 2019, p. 231).

\subsubsection{Viñedos y turismo sostenible}

$\mathrm{Si}$, como es sabido, el término sostenibilidad alude al equilibrio entre las consideraciones de tipo ambiental, social y económico que se pueden inferir en cualquier territorio, en los paisajes del viñedo podemos constatarlo de formas diversas. La tradición histórica de este cultivo permite descubrir cómo los paisajes resultantes aportan unos valores ambientales intrínsecos, al adaptarse a unos condicionantes naturales que dotan de sentido a la explotación y que expresan la conservación de los recursos naturales; unos valores culturales y sociales basados en la identificación de elementos que puedan entenderse como patrimonio, que también generan emociones y sentimientos dentro de una experiencia vivida, contribuyendo a respetar la autenticidad sociocultural de las comunidades anfitrionas; y, por supuesto, económicos, derivados de la capacidad de atracción que puedan tener las explotaciones a medio y largo plazo, sin obviar las actividades propiamente productivas orientadas al mercado del vino.

Para deducir la potencialidad de cada una de estas dimensiones, se parte de distintas aproximaciones teóricas (Figura 1) que revelan la importancia de aspectos clave como son el estado del propio paisaje, en relación con la conservación de los paisajes del viñedo, y los elementos vinculados con el patrimonio material e inmaterial, en relación con la autenticidad y valorización de dichos paisajes. Así, se ponen de relieve aquellos valores paisajísticos y patrimoniales, tanto materiales como inmateriales, que refuerzan la apuesta por la conservación ambiental y cultural, y que en última instancia, aseguran su viabilidad económica. Por su parte, las aproximaciones teóricas que se han elegido para el análisis de las potencialidades de los paisajes del viñedo en relación con los planteamientos de turismo sostenible son de dos tipos: las relacionadas con la valorización del patrimonio agrario, que ya hemos analizado, y las vinculadas con los servicios ecosistémicos culturales, en las que profundizaremos a continuación.

La óptima conservación de los recursos naturales, en este caso el paisaje, además de todos los activos patrimoniales que acabamos de exponer, sirve también para generar o provocar sentimientos y emociones surgidos de la experiencia turística. Los beneficios, de naturaleza inmaterial, que se derivan del disfrute 
de ecosistemas, de paisajes, de localizaciones o de lugares se identifican con lo que Naciones Unidas ha venido denominando como Servicios Ecosistémicos Culturales (SEC). Esta clase de servicios promueven el enriquecimiento espiritual, la salud mental, el desarrollo cognitivo, la reflexión, y la experiencia estética y recreativa de las personas que los habitan, los trabajan y los disfrutan, todos de posible aplicación a partir de la revalorización patrimonial y el desarrollo del ecoturismo.

Figura 1. Turismo sostenible y su aplicación a los paisajes del viñedo

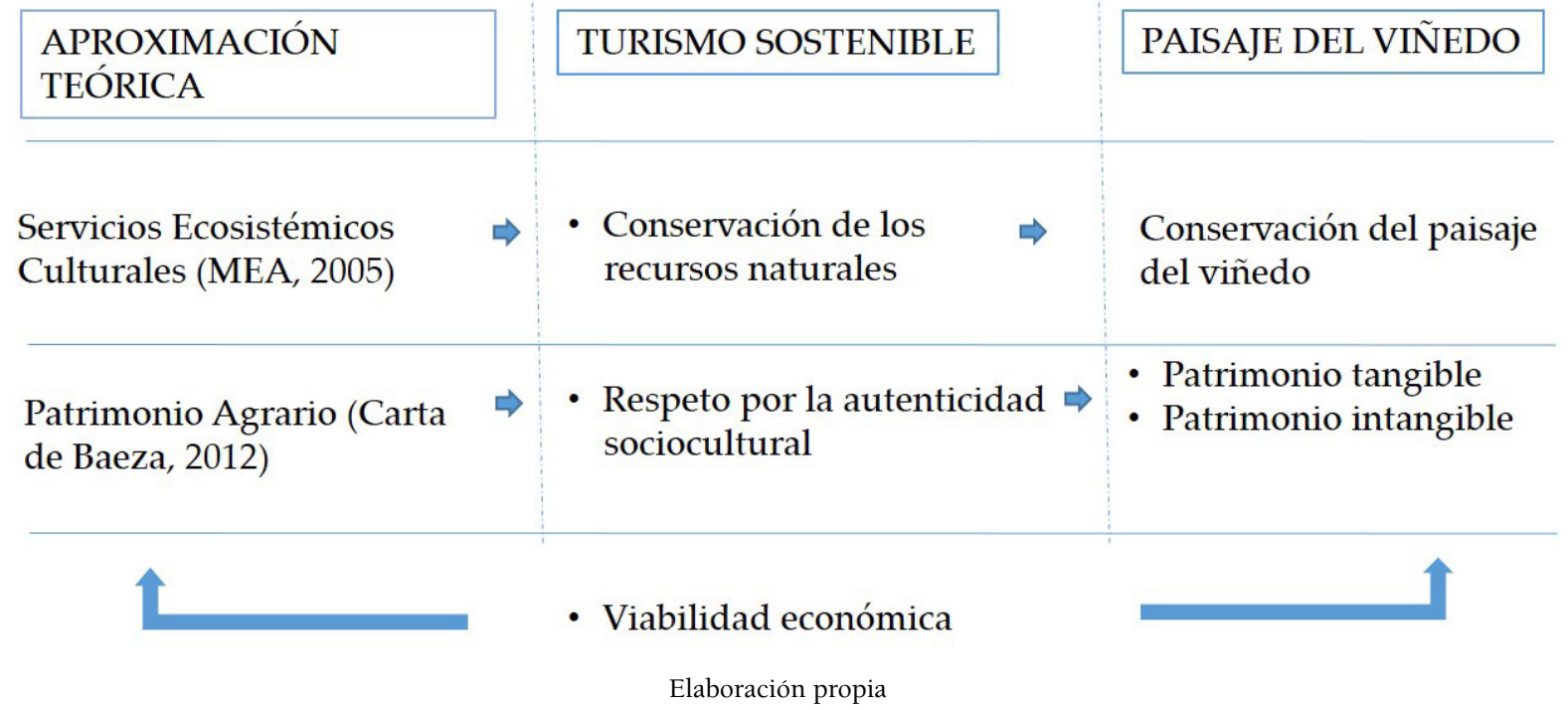

Por consiguiente, los paisajes pueden ofrecer un amplio abanico de servicios experienciales e intelectuales que serán de distinta naturaleza si el contacto con el medio se realiza de una manera activa o pasiva. Cuando el contacto es "activo" permite fomentar, de manera directa, la experiencia sensorial, estética y contemplativa; mientras que el refuerzo de la investigación científica, la educación, la cultura, la revalorización del patrimonio y la definición de símbolos y significados religiosos responden a un contacto "pasivo" (Haines-Young y Potschin, 2017, p. 6).

Los SEC conectan con el análisis de los paisajes culturales, entendidos como "resultado de la acción en el tiempo de las personas y el medio natural, cuya expresión es un territorio percibido y valorado por sus cualidades culturales, producto de un proceso y soporte de la identidad de una comunidad" (Cruz, 2015 , p. 13), vinculados con determinado tipo de actividades y procesos. Por su parte, el patrimonio, bajo el enfoque propuesto por los SEC, incluye objetos históricos y aspectos intangibles que fomentan la identidad colectiva (Tengberg et al. , 2012), simbolizando modos de vida que la población comparte y que se proyectan en actividades creativas y ceremoniales, que contribuyen al bienestar humano en términos de las identidades proyectadas y las experiencias derivadas (Fish, Church y Winter, 2016). Por consiguiente, una nueva apuesta por la concepción del "territorio entendido como patrimonio", es decir, como un bien cultural complejo que se descompone en capas espaciales y temporales, y cuyo valor recae en atributos materiales e inmateriales (Silva y Fernández, 2017; Cañizares, 2017). De forma específica, todo ello podemos aplicarlo al análisis de los paisajes culturales agrarios en base a sus características físicas y humanas, y al patrimonio agrario en ellos contenido.

Respecto a los paisajes del viñedo, reconocemos una importante diversidad de servicios a la población por su naturaleza dinámica y cultural. Ya hemos mencionado cómo las específicas interrelaciones entre los elementos físicos y humanos a lo largo de la historia han dado lugar a un rico patrimonio material e inmaterial de variada tipología, fomentando la percepción de los espacios rurales como lugares representativos de valores como la belleza, la tranquilidad, la autenticidad, el valor cultural, etc.,. Para la caracterización de los SEC, contamos como base el estudio elaborado por Winkler y Nicholas en 2016, quienes identifican hasta un total de 12 tipos de servicios ecosistémicos proporcionados por los paisajes del viñedo, aportación que se puede complementar con otras aproximaciones teóricas a otro tipo de ecosistemas o emplazamientos, como los paisajes culturales, en general, o los agrarios, en particular (Plieninger, Dijks, Oteros-Rozas, Bieling, 2013; Berkel y Verburg, 2014; Winkler y Nicholas, 2016) (Tabla 2). 
Paisajes del viñedo, turismo y sostenibilidad: interrelaciones teóricas y aplicadas

Tabla 2. Indicadores propuestos como SEC en recientes estudios e investigaciones

\begin{tabular}{|l|l|l|l|}
\hline \multicolumn{1}{|c|}{$\begin{array}{c}\text { Millenium Ecosystem } \\
\text { Assessment (2005) }\end{array}$} & $\begin{array}{c}\text { Paisaje cultural } \\
\text { Plieninger, et al., (2013) }\end{array}$ & \multicolumn{1}{c|}{$\begin{array}{c}\text { Paisaje agrario } \\
\text { Berkel y Verburg (2014) }\end{array}$} & $\begin{array}{c}\text { Paisaje del viñedo } \\
\text { Winkler y Nicholas (2016) }\end{array}$ \\
\hline Diversidad cultural & Servicios espirituales & Recreación & Existencia \\
\hline Valores espirituales y religiosos & Valores educacionales & Belleza estética & Legado \\
\hline Sistemas de conocimiento & Inspiración & Patrimonio cultural & Físico \\
\hline Valores educacionales & Valores estéticos & Inspiración & Experiencial \\
\hline Inspiración & Relaciones sociales & Espiritualidad & Científico \\
\hline Valores estéticos & Sentimiento de lugar & & Educativo \\
\hline Relaciones sociales & Patrimonio cultural & & Entretenimiento \\
\hline Sentimiento de lugar & Recreación y ecoturismo & & Estético \\
\hline Patrimonio cultural & Intranquilidad & & Patrimonio \\
\hline Recreación y ecoturismo & Nivel de miedo & & Simbólico \\
\hline & Nivel de ruido & & Espiritual \\
\hline
\end{tabular}

Elaboración propia

Podemos observar que existen una serie de servicios como la inspiración, la espiritualidad, el patrimonio cultural y la recreación que se repiten en cada uno de los estudios y que son, a priori, fácilmente identificables en los paisajes del viñedo (Figura 2). El primero, la inspiración, se identifica como motor de creación artística (literaria, pictórica,...), y también en relación con la arquitectura, los símbolos identitarios y el folclore, con lo que contribuye, decididamente, a la generación del patrimonio cultural, tanto con elementos materiales como inmateriales. Aplicada a los paisajes del viñedo tendría relación con aspectos tan diversos como bienes muebles en el caso de obras literarias y/o pictóricas, bienes inmuebles singulares como las construcciones tradicionales y, sobre todo, con el patrimonio inmaterial relacionado con los usos y costumbres en base a las tradiciones de cada territorio.

Figura 2. Paisaje del viñedo en Laguardia, Rioja Alavesa (Álava, España)

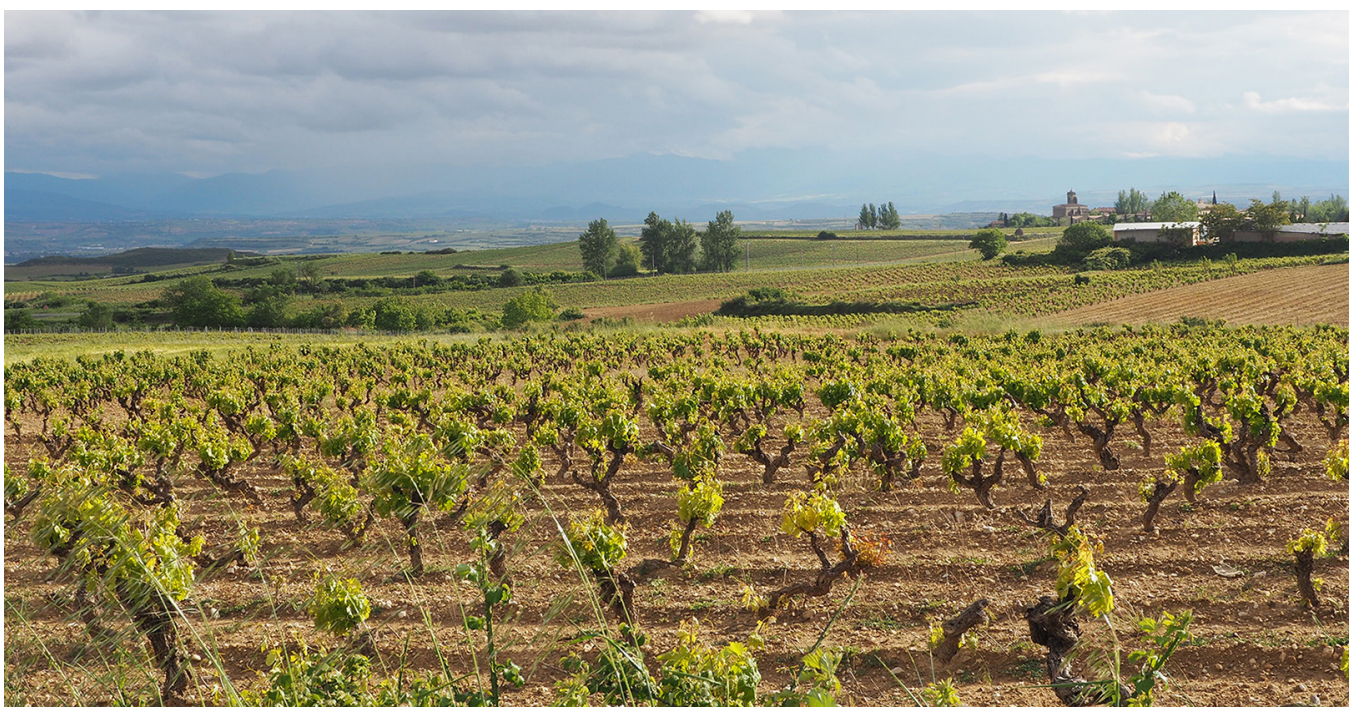

Fotografía de los autores

La espiritualidad y religiosidad se vincula con aquellos elementos que son considerados valiosos para la comunidad por su significado tribal o fetichista. En el caso de los viñedos, resulta fácil identificar estos elementos del patrimonio inmaterial, agrupados en creencias, rituales y actos festivos representativos del papel de la religiosidad en el santoral y en las festividades asociadas, mayormente, a la fertilidad. Respecto al patrimonio cultural, en nuestro caso lo asociamos con el específicamente agrario, los bienes generados o aprovechados por la actividad agraria a lo largo del tiempo, cuya variedad ya hemos expuesto anteriormente en relación con los paisajes del viñedo. Finalmente, en el caso de la recreación, los paisajes 
del viñedo se relacionan directamente con diversas tipologías de turismo como el ecoturismo, el turismo rural y, de manera más específica, el enoturismo, todos ellos bajo el paraguas de la sostenibilidad. En este sentido, el estudio de Winkler y Nicholas (2016) evidencia que todos los SEC planteados en las entrevistas en profundidad tienen la máxima correspondencia con los principios del turismo sostenible, y en concreto con la conservación del medio natural, mientras que el sentimiento existencial y recreativo estaría más vinculado con la experiencia en su conjunto, dando cabida a la dimensión cultural y económica del turismo sostenible.

\subsection{Interrelaciones aplicadas: consideraciones del turismo sostenible en los Pagos Vitivinícolas}

La diferenciación de la producción alimenticia a partir de sellos y certificaciones de calidad se ha convertido en una interesante estrategia comercial en los actuales mercados globalizados (Tregear, Arfini, Belletti, Marescotti, 2007; Lorenzini, 2010). La singularidad de las producciones descansa, principalmente, en el papel que juegan los factores geográficos en la caracterización del producto final. Su descubrimiento tiene cierta potencialidad y puede considerarse como un recurso turístico de interés en la sociedad actual, puesto que a través de los factores geográficos, naturales y culturales, se puede identificar un sistema de conocimientos basados en la interacción racional con la naturaleza, el peso de la tradición y el saber hacer, reflejo de una identidad territorial o local específica que, en algunos casos, goza de gran arraigo y fortaleza.

Los vinos reconocidos con certificaciones de calidad aglutinan todos estos aspectos, siendo muy representativos en las Denominaciones de Origen propias o Vinos de Pago, donde pequeñas unidades de producción ejemplifican una serie de relaciones ambientales y culturales que dotan de valor añadido a un producto. A pesar de que la orientación prioritaria de este tipo de explotaciones es económica, reiteramos que expresan unas interacciones naturales y culturales únicas que son susceptibles de ser aprovechadas para la oferta turística. Frecuentemente, además, "los procesos de patrimonialización de los paisajes del viñedo se hallan estrechamente vinculados a un producto de calidad con proyección internacional y al fomento de la actividad turística en un contexto de fuerte competitividad territorial" (Porcal, 2019, p. 237).

De los estudios de caso planteados en el apartado metodológico, consideramos que el principal atractivo de los Pagos Vitivinícolas (lugares donde se elaboran vinos de pago) es la comprensión de cómo los diferentes elementos ambientales del territorio determinan la obtención de unos vinos de gran calidad. Este tipo de relaciones se explican a los visitantes a pie de parcela, teniendo la oportunidad de poderlas descubrir, de forma sensorial, no solo visualmente, sino sobre todo, en la cata que se realiza a continuación. En las visitas identificamos el elemento paisaje como eje vertebrador de la experiencia, en relación con los elementos que lo caracterizan y contribuyen al éxito de las mismas, generalmente incorporando al recorrido algún punto de la explotación en el que se pueda visualizar una panorámica del conjunto de los viñedos.

De manera concreta, en la elaboración de estos vinos de gran calidad, encontramos, entre los factores más determinantes, la propia configuración del relieve y de sus componentes (geología, litología, pendientes, etc.); los condicionantes climáticos (temperaturas, precipitaciones, etc.), entre los que sobresale la influencia de la insolación; el tipo y textura del suelo; la presencia de vegetación y plantas aromáticas; la existencia o ausencia de agua; las técnicas naturales de abonado, y el proceso de elaboración del producto desde el tratamiento de las vides, pasando por la vendimia, hasta su finalización en bodega, principalmente.

En los viñedos escogidos, Pago de Los Balagueses (Valencia) y Pago Dehesa del Carrizal (Ciudad Real) destacan, sobre los demás, algunos elementos relacionados con el medio natural. La ubicación de estos viñedos en territorios determinados por una singular configuración del relieve, junto con condicionantes edafológicos específicos, son fundamentales para imprimirles su carácter único. Así, encontramos dos Pagos en los que la altitud media es elevada y la propia orografía determina una mayor humedad y menor exposición al sol, dando lugar a vinos con más frescura o mayores propiedades atlánticas, muy destacables, si cabe, cuando estamos hablando de explotaciones que se ubican en zonas del interior peninsular (climas Cs siguiendo la clasificación de Köppen), con fuertes rasgos continentales en su climatología. Por su parte, la vegetación supone uno de los factores ambientales clave, ya que los casos estudiados hablan de la sucesión de parcelas que, ubicadas a una considerable altura, se encuentran encajadas entre pequeñas 
elevaciones rodeadas de vegetación natural, lo que garantiza no sólo un limitado efecto de determinados tipos de viento, sino también la preservación de los valores agronómicos del viñedo, específicos al no estar rodeados de parcelas agrícolas vecinas y evitando, en consecuencia, la contaminación por fitosanitarios, muy evidente en Pago de Los Balagueses (Figura 3). A estos microclimas se le añade la presencia de tomillos, romeros y otras hierbas mediterráneas que trasladan sus propiedades aromáticas al vino final, y que son percibidas en las catas guiadas y por el público especializado. Finalmente, la textura y tipo de suelo juegan un papel primordial. En Pago Los Balagueses nos encontramos en la España caliza, con unos suelos de textura bastante aterronada y porosa, lo que facilita la oxigenación, y que orgánicamente presentan cierta riqueza. Por su parte, en Pago Dehesa del Carrizal, dentro de la España silícea, el sustrato edáfico, más lixiviado, proviene de la erosión y del transporte de sedimentos de los montes colindantes, corrigiendo las limitaciones de acidez propias de los suelos silíceos mediante técnicas agronómicas que persiguen enriquecerlos a través del sembrado de cereales entre las hileras de viñedo (Figura 4).

Figura 3. Disposición del viñedo y vegetación natural circundante en Pago Los Balagueses (Valencia, España)

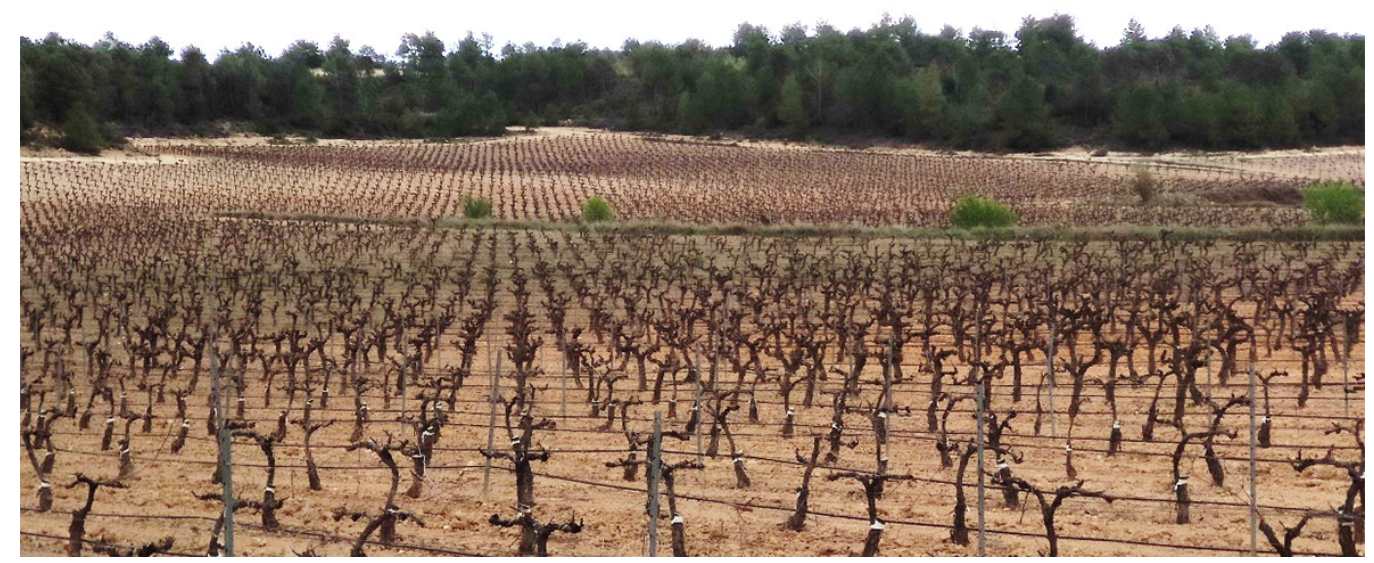

Fotografía de los autores

Figura 4. Hileras de cereales entre vides en Pago Dehesa del Carrizal (Ciudad Real, España)

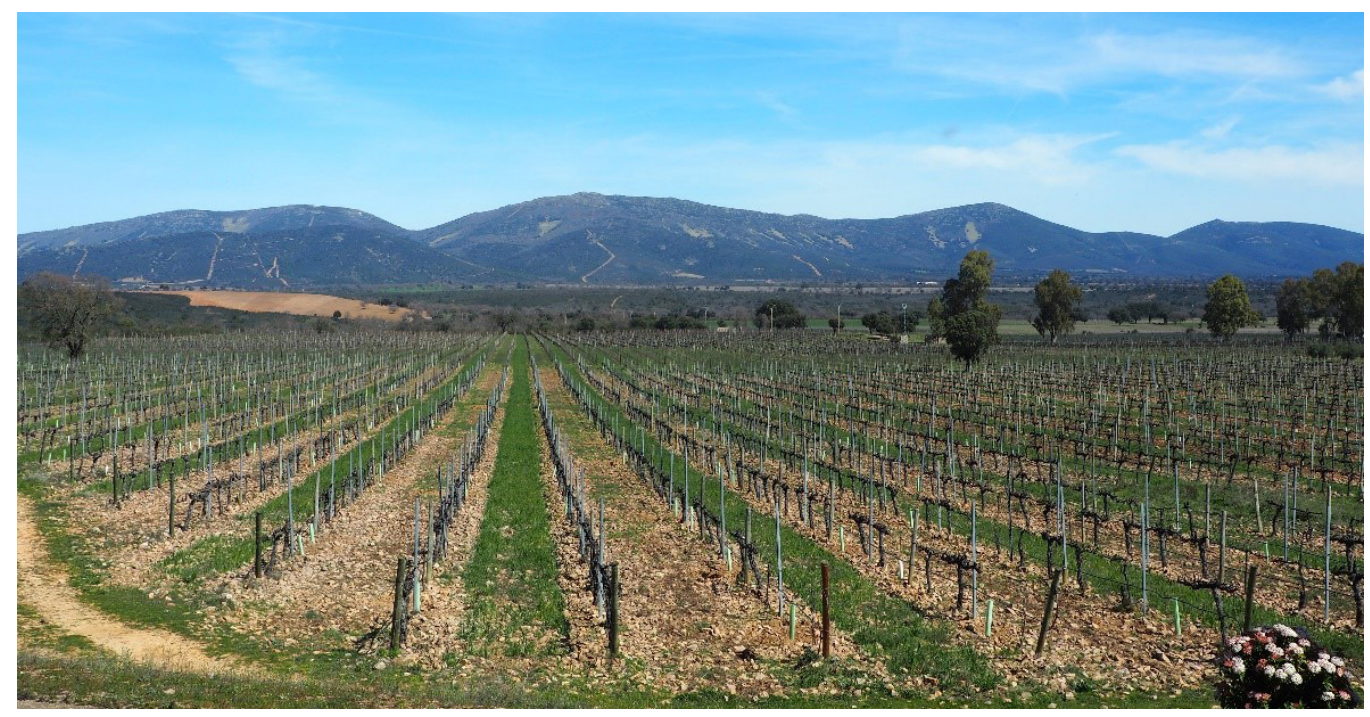

Fotografía de los autores

En suma, la experiencia turística parte de una lección sobre la continua interacción de elementos ambientales que favorece, entre otras cosas, la correcta valorización del entorno y del producto final, donde 
el paisaje y su contemplación permiten descubrir un interesante servicio cultural derivado de valores intangibles como la tranquilidad y el saber hacer. Desde esta perspectiva social y cultural, junto con la inmersión territorial que supone la contemplación de los viñedos, los principales atractivos turísticos se basan, sobre todo, en el proceso de elaboración de los vinos certificados. La explicación de los exigentes estándares de calidad que deben cumplir todos los Vinos de Pago supone una importante fuente de conocimientos sobre cómo los aspectos agronómicos, químicos, enológicos y culturales se coordinan para producir un alimento único. Factores como la cosecha en verde, la vendimia a mano, la equilibrada relación entre humedad y temperatura de las salas de crianza, o la correcta elección del tipo de barrica son saberes que responden, de alguna manera, a la creciente necesidad de información sobre la salubridad de los alimentos, los correctos procesos de elaboración, la estructura de la cadena de distribución, su sostenibilidad, etc., por parte de la sociedad actual.

Respecto al nivel de integración con las comunidades locales, precepto preferente para la OMT, se constata, en ambos casos, el conocimiento de la explotación (Pago) por parte de la mayor parte de la población que habita en los municipios colindantes. Se trata, en general, de pequeños núcleos y aldeas que contribuyen con mano de obra en las labores de las viñas y que ofrecen los vinos en sus servicios de restauración. Más cuestionable es el nivel de adecuación de la bodega con el patrimonio arquitectónico local o la transmisión de saberes locales y culturales que no sean los estrictamente vinculados con la elaboración de los vinos. Ello se constata, por ejemplo, en la introducción de nuevas variedades de vid que no son autóctonas o tradicionales, predominando, desde el punto de vista genético, las varietales francesas como la Syrah o la Cabernet Sauvignon, bien porque las bodegas sean relativamente recientes, como ocurre en Pago de Los Balagueses, o porque el cultivo de la vid no goza de tradición histórica, como ocurre en el caso de Pago Dehesa del Carrizal, ubicado en una comarca de tradición pecuaria. En este punto, cabe reseñar los esfuerzos realizados por Pago Los Balagueses para recuperar el patrimonio natural relacionado con variedades tradicionales como la Bobal, aunque con una limitada producción dentro de la Denominación de Origen Utiel-Requena.

Desde un punto de vista económico, la actividad turística es todavía incipiente en ambos Pagos. Las experiencias se basan en recorridos por la explotación con la posibilidad de cata al final de los mismos, complementados con otras actividades asociadas a la restauración u organización de eventos familiares lo que supone, por término medio, de un 5 a un $10 \%$ de los ingresos totales. Resaltar el valor añadido de los vinos de Pago es uno de los objetivos esenciales de la oferta de enoturismo, ya que el visitante suele desconocer la importancia de este sello de calidad. El énfasis se pone sobre las diferencias de estas certificaciones respecto a otras marcas de vino que añaden la palabra "Pago" en su etiquetado y no ofrecen Vinos de Pago certificados, o en que existan asociaciones como "Grandes Pagos de España", que aglutinan a bodegas que ostentan, o no, dicha certificación. El desconocimiento de la verdadera figura de Pago Vitivinícola para el público en general, posibilita que mediante la visita, el turista sepa valorar las propiedades de unos vinos excepcionales, finalizando, un $90 \%$ de ellas, en la compra de vino, así como que los productores reivindiquen la especificidad y la calidad de sus productos.

Se subraya, por parte de los responsables de las explotaciones, que las actividades turísticas se encuentran aún en una fase inicial, pero que pensando bien las iniciativas, sus viñedos ofrecen amplias perspectivas de desarrollo en el futuro más cercano para la oferta enoturística. En ese sentido, se aboga por que la ampliación de esta oferta se realice de forma gradual, incorporando a profesionales especializados, tal y como sucede en Pago Los Balagueses.

\section{Discusión de resultados}

En estas dos iniciativas se constata que el turismo realizado en los viñedos se basa en el disfrute de una experiencia que podríamos considerar completa y única (Carlsen, 2004; Hall, Longo, Mitchell, y Johnson, 2000; Gravari-Barbas, 2014; Baraja, Herrero, Martínez y Plaza Gutiérrez, 2019). Completa, en primer lugar, porque desarrolla una amplia oferta de actividades, pasando desde la visita a una bodega, hasta la degustación o contemplación paisajística de los viñedos, donde el paisaje "asume un papel protagonista, pues se vincula la calidad del producto con la calidad del lugar" (Baraja, et al., 2019, p. 101); y en segundo lugar, única, porque la experiencia se vive de manera exclusiva en un paraje determinado, con una singular combinación de aspectos naturales y culturales, respondiendo a lo que se ha identificado como turismo de terroir (Hall y Mitchell, 2002, p. 73), que en los casos analizados adquiere todo su 
significado. En consecuencia, queda demostrado el fuerte nexo de unión entre el paisaje y la calidad del producto turístico, donde la diversificación de rentas sería el reto común de productores, de agencias de turismo y de consumidores (Getz y Brown, 2006).

El debate sobre los resultados obtenidos se centra en las potencialidades que ofrece el turismo en relación con los paisajes del viñedo para la actividad turística sostenible, en un intento de abordar la hipótesis y el objetivo planteados.

Puesto que enfocamos esta temática desde un punto de vista teórico y práctico, repasaremos la documentación internacional que marca la hoja de ruta en el turismo sostenible, destacando aquellos aspectos relacionados con los paisajes del viñedo y, en concreto, con los estudios de caso planteados. La Carta Mundial del Turismo, firmada en Lanzarote en 1995, ya reconocía que el desarrollo turístico debía "ser soportable ecológicamente a largo plazo, viable económicamente y equitativo desde una perspectiva ética y social para las comunidades locales", aspectos solo alcanzables a partir de una planificación adecuada que consideramos imprescindible para la práctica del turismo en relación con los paisajes del viñedo, especialmente en los Pagos Vitinícolas. Esta actividad se integra "en el entorno natural, cultural y humano", como recoge la Carta, así como contribuye al reconocimiento de "las tradiciones de las comunidades locales, y el apoyo a su identidad, cultura e intereses"; "la participación de todos los actores implicados en el proceso y a todos los niveles: local, regional, nacional e internacional"; y en ella "la conservación, la protección y la puesta en valor del patrimonio natural y cultural representa un auténtico reto cultural, tecnológico y profesional", entre otros aspectos destacables. Consideramos que en las explotaciones analizadas se realiza este esfuerzo de integración, especialmente cuando intentamos valorizar, en su justa medida, los condicionantes derivados del patrimonio natural. Más cuestionable puede ser la relación con las tradiciones de las comunidades locales, pues una parte importante de los Vinos de Pago responden, en su gran mayoría, a iniciativas empresariales que tienen como objetivo satisfacer los segmentos de demanda más cualificados. De todas formas, no olvidemos que las comunidades locales conocen estas iniciativas y además participan como mano de obra estable y estacional.

Con el Código Ético Mundial para el Turismo, publicado en 1999, la OMT aportó un conjunto de principios concebidos para orientar a los principales actores del desarrollo turístico, con el objetivo de maximizar los beneficios del sector, minimizando las posibles consecuencias negativas para el medio ambiente, el patrimonio cultural y las sociedades. En relación con sus 10 artículos, el turismo en los paisajes del viñedo, y de manera específica en los Pagos Vitivinícolas estudiados, responde claramente a algunos de ellos (OMT, 1999):

- Contribuye al "entendimiento y respeto mutuos entre hombres y sociedades" (art.1) a través de la puesta en valor de una actividad agraria.

- Es "instrumento de desarrollo personal y colectivo" (art.2), así como factor de desarrollo sostenible (art.3), a partir de una planificación adecuada.

- Es factor de "aprovechamiento y enriquecimiento del patrimonio cultural de la humanidad" (art.4), en relación con los paisajes culturales agrarios incluidos en la Lista del Patrimonio Mundial UNESCO. Y, por supuesto, es "beneficioso para las comunidades de destino" (art.5), en las que la actividad turística contribuye a completar las rentas, generalmente vinculadas al sector primario, y dinamiza las economías locales.

De manera concreta, la Carta Europea del Enoturismo (2015), partiendo del desarrollo de actividades turísticas, de ocio y tiempo libre dedicadas al descubrimiento y disfrute cultural y enológico de la viña, el vino y su territorio, puntualiza que los "territorios vitivinícolas deben comprometerse y dar prioridad absoluta a los principios del desarrollo sostenible". Deben jugar un rol determinante en la conservación, gestión y valorización de los bienes territoriales, y asumir en las experiencias concretas el valor de modelo, tanto en sus objetivos como en la metodología de aplicación, así como asumir su responsabilidad en la relación entre el territorio y su explotación, cuestiones que consideramos que se cumplen en los Pagos Vitivinícolas. Además, insiste en que los recursos territoriales y vitivinícolas deben ser tutelados, preservados y cuidadosamente gestionados (salvaguardados de su vulnerabilidad), para estar siempre disponibles (utilización individual y económica por parte del territorio), acción que no debe perjudicar la supervivencia de otras especies animales o vegetales del ecosistema.

En nuestro contexto más inmediato, la Unión Europea (U.E), destacamos la Agenda para un turismo europeo sostenible y competitivo (Comisión Europea, 2007), con el objetivo múltiple de favorecer la 
prosperidad económica, la equidad y cohesión social, la protección del medio ambiente y la cultura. Especialmente significativa es la alusión a la necesidad de plantear políticas adecuadas que proporcionen una gestión sostenible de los destinos, aspecto transversal y muy importante en el turismo practicado en el medio rural. De los principios expuestos, el turismo en relación con los paisajes del viñedo contribuye a proporcionar un enfoque global e integrado, puede y debe plantear actividades a largo plazo "velando por las necesidades tanto de las generaciones futuras como las actuales"; permite "respetar las características de los destinos", implicar a "todas las partes interesadas" y evaluar "la capacidad de acogida", siempre a partir de una correcta planificación territorial ${ }^{4}$. Aspectos constados en los estudios de caso presentados.

El turismo basado en el disfrute del paisaje cultivado, en este caso de los viñedos calificados como Pagos, y de su patrimonio agrario asociado, puede contribuir a la creación de conciencia ambiental, proteger la fauna y la flora silvestres, la diversidad biológica, los ecosistemas, la diversidad cultural y aumentar el bienestar y los medios de vida de las comunidades locales, por lo que debe ser apoyado, como otras tipologías de turismo, siguiendo el documento El futuro que queremos que surge de la Cumbre de la Tierra Río+20 (2012), en el que se cita expresamente el turismo sostenible.

Atendiendo a la contribución más reciente y relevante, aprobada en el Word Summit on Sustainable Tourism +20 , celebrado en la ciudad de Vitoria (España) en 2015, la Carta Mundial del Turismo Sostenible +20 , que actualiza anterior de 1995, el turismo relacionado con los paisajes del viñedo contribuye al respeto y la puesta en valor de "las tradiciones y el conocimiento local", clave en la promoción turística de los Pagos, y además, permite "promover la participación plena de las comunidades locales (...) en las decisiones que les afectan en los proyectos de desarrollo turístico", como se indica en su preámbulo. Precisamos, también, en relación con lo expuesto en este documento, que los paisajes del viñedo favorecen un turismo entendido como "actividad transversal" que contribuye a luchar contra la pobreza, proteger la naturaleza y medio ambiente, y promover el desarrollo sostenible:

- Qué, bien gestionado, puede "ser protagonista trascendental a la hora de preservar los tesoros actuales para las generaciones futuras, asegurando la protección y la integridad de nuestro patrimonio común, material e inmaterial", en este caso vinculado a la cultura del vino.

- Puede, también, "ser compatible con la conservación de la naturaleza y la biodiversidad".

- Es uno de los "motores más prometedores de crecimiento de la economía".

- Constituye "una fuerza motriz del patrimonio cultural, las artes y las industrias culturales y creativas, de conformidad con las convenciones culturales de la UNESCO y sus directrices operacionales". Buena muestra de ello son los paisajes culturales agrarios relacionados con los viñedos incluidos en la Lista del Patrimonio Mundial. De hecho, se realiza un llamamiento a los gobiernos e instituciones a "utilizar los sitios designados por la UNESCO como lugares de aprendizaje para fomentar la integración armoniosa del turismo con el patrimonio cultural y natural".

- Como destinos turísticos, estos paisajes y, en general, las áreas rurales deben incluir a todas las partes interesadas, empoderar a las comunidades locales y facilitar la planificación, maximizar los beneficios económicos, preservar sus valores evaluando amenazas, riesgos y oportunidades, capacidad de carga, etc., y promover actividades educativas y de divulgación.

Especialmente importante, en relación con el tema tratado, nos parece la atención que la Carta presta a una cuestión clave: "preservar nuestro patrimonio común", en este caso, el patrimonio agrario. Partiendo de la idea de que "el turismo puede y debe reforzar el decisivo papel del patrimonio, tanto material como inmaterial, en la sociedad contemporánea, consolidando la identidad y la diversidad cultural", ello puede determinar el desarrollo de muchos destinos.

Más recientemente, la declaración de 2017 como Año Internacional del Turismo Sostenible para el Desarrollo incidía, de nuevo, en "los valores culturales, la diversidad y el patrimonio" como una de sus cinco áreas clave. La campaña "Travel, Enjoy, Respect" (OMT, 2017b), vinculada con este evento, en su fomento del turismo responsable también alentaba, entre otras muchas cosas, a "disfrutar todo aquello que hace de un destino internacional un lugar único y diferente", así como a "adquirir productos y artículos de artesanía fabricados en la zona" y pagar "un precio justo", aspecto éste último perfectamente aplicable a la oferta turística o enoturística que pueden ofrecer los Pagos Vitivinícolas, donde la relación

4 En 2013 se publicaría la Guía de la UE sobre el turismo sostenible para el desarrollo. 
calidad-precio suele está muy optimizada. Valgan los ejemplos de la marca "Los Balagueses Syrah 2015" del Pago del mismo nombre, vino que obtuvo el sexto puesto mundial de vinos cuyo precio es inferior a los 30 euros según la prestigiosa lista de James Suckling; o las medallas de plata en el concurso mundial de Bruselas de las variedades Cabernet Sauvignon y Syrah correspondientes a Pago Dehesa del Carrizal, con precios que no superan los 20 euros por botella.

\section{Conclusiones}

Los paisajes del viñedo presentan una serie de singularidades que refrendan su carácter cultural y patrimonial. Desde el punto de vista cultural, se trata de un aprovechamiento con un indiscutible trasfondo histórico en Europa, y especialmente en España, ligado en sus orígenes a la expansión del Imperio Romano. Además, es claro resultado de un medio físico determinado y de unas capacidades de transformación del mismo por parte del hombre, que se ha tenido que adaptar a él para poder sobrevivir con técnicas que han ido evolucionando en el tiempo y han permitido el cultivo de la vid con diversas funciones socioeconómicas. Su carácter cultural también tiene una dimensión social, gracias a la fortaleza del modelo de agricultura familiar, de tipo directo, que se complementa con un sólido sector agroindustrial dedicado a la elaboración, transformación y distribución comercial, con cientos de empleos indirectos; a la vez que se configura como un elemento de identidad fundamental para las poblaciones locales en las que este cultivo ha supuesto su principal medio de vida, asociado a un patrimonio material amplio, principalmente de tipo constructivo (bodegas,...), e inmaterial (tradiciones, folclore, fiestas,...), aún muy arraigado. Estos aspectos son claramente representativos en los viñedos de Castilla-La Mancha y constatables en áreas concretas como las ofrecidas por los Pagos Vitivinícolas.

El análisis realizado nos ha permitido profundizar en las relaciones entre los paisajes agrarios, en concreto los derivados del cultivo de la vid (viñedos) y sus potencialidades para formar parte de estrategias de turismo sostenible. A partir de las bases metodológicas proporcionadas por la literatura científica, el análisis de los Servicios Ecosistémicos Culturales (SEC) y los presupuestos sobre el patrimonio agrario expresados en la Carta de Baeza, hemos expuesto cómo los paisajes del viñedo debido a su carácter cultural, su riqueza patrimonial así como los servicios ecosistémicos con ellos asociados, avalan su sostenibilidad en relación con la actividad turística, siempre con unos criterios de planificación adecuados.

De forma aplicada, los Pagos certificados presentan un gran potencial para promover fórmulas de turismo sostenible. Consideramos que la reducida escala territorial y los exigentes estándares de calidad que deben cumplir, basados en la interacción de los elementos ambientales y culturales, constituyen factores clave a la hora de confirmar su idóneo papel para implementar fórmulas de turismo sostenible. En estos Pagos, el respeto por el paisaje, el saber hacer de sus gentes, el papel de los factores naturales, y los mencionados estándares de calidad, propicia una experiencia muy atractiva que puede ser completada con otros productos turísticos de especial valor territorial como la cercanía a zonas de importante valor ecológico y cultural, principalmente espacios naturales protegidos. No obstante, no hay que olvidar que estos distintivos de calidad tienen una orientación claramente económica, y no es posible cumplir notoriamente con todos los parámetros del turismo sostenible propuestos por la OMT. De las experiencias visitadas se constata que la ubicación dentro de un área tradicional, como sucede en el Pago de Los Balagueses, o en la proximidad de un Parque Nacional, en el caso del Pago Dehesa del Carrizal, constituyen factores meramente circunstanciales, aunque, de alguna manera, refuerzan las posibilidades de promover y diseñar otro tipo de estrategias turísticas en el futuro más cercano.

\section{Financiación}

Esta investigación está asociada al Proyecto de Investigación "Los Paisajes Culturales Agrarios en Castilla-La Mancha como base del desarrollo territorial" (SBPLY / 19/180501/000041), financiado por la Junta de Comunidades de Castilla-La Mancha (España) y por los Fondos FEDER.

\section{Referencias}

Almirón, A., Bertoncello, R., \& Troncoso, C. (2006). Turismo, patrimonio y territorio. Una discusión de sus relaciones a partir de casos de Argentina. Estudios y Perspectivas en Turismo, 15(2), 121-124. 
Baraja, E., Herrero, D., Martínez, M., \& Plaza Gutiérrez, J.I. (2019). Turismo y desarrollo vitivinícola en espacios de montaña con "alta densidad patrimonial". Cuadernos de Turismo, (43), 97-122. https://doi. org/10.6018/turismo.43.04

Bell, D. (2006). Variations on the rural idyll. In P. Clocke, T. Marsden, P., \& Mooney, P. (Eds.), The Handbook of Rural Studies (pp. 149-160). https://doi.org/10.4135/9781848608016.n10

Berkel, D.B., \& Verburg, P.H. (2014). Spatial quantification and valuation of cultural ecosystem services in an agricultural landscape. Ecological indicators, (37), 163-174. https://doi.org/10.1016/j. ecolind.2012.06.025

Cañizares, M.C. (2017). Paisaje, Patrimonio e Identidad Territorial: claves históricas y desafíos actuales. En F. Allende, R. Cañada, G. Fernández-Mayorales, G. Gómez, N. López, A. Palacios, ... \& M.J. Vidal (Eds.), Naturaleza, territorio y ciudad en un mundo global (pp. 1725-1744). Madrid: Ed. Asociación de Geógrafos Españoles y Universidad Autónoma de Madrid.

Cañizares, M.C., \& Ruiz, A.R. (2014). Evolución del paisaje del viñedo en Castilla-La Mancha y revalorización del patrimonio agrario en el contexto de la modernización. Scripta Nova Revista Electrónica de Geografía y Ciencias Sociales, vol. XVIII, (498), 30 p. Recuperado de https://revistes. ub.edu/index.php/ScriptaNova/article/view/15082

Carlsen, J. A (2004). Review of Global Wine Tourism Research. Journal of Wine Research, 15(1), 5-13. https://doi.org/10.1080/0957126042000300281

Carta del Turismo Sostenible (1995). Lanzarote (España). Recuperado de https://viajealasostenibilidad. org/documentos/carta-del-turismo-sostenible/

Carta Europea del Enoturismo (2015). París: RECEVIN. Recuperado de http://centrointegraldelvino.org/ onewebmedia/Charte_ES.pdf

Carta Mundial de Turismo Sostenible (2015). Vitoria (España). Recuperado de http:// cartamundialdeturismosostenible2015.com/wp-content/uploads/2016/05/Carta-Mundial-deTurismo-Sostenible-20.pdf

Castillo, J. (Dir.) (2013). Carta de Baeza sobre el Patrimonio Agrario. Sevilla: Universidad Internacional de Andalucía. Recuperado de https://www.unia.es/explorar-catalogo/item/carta-de-baeza

Comisión Europea (1999). Estrategia Territorial Europea. Hacia un desarrollo equilibrado y sostenible del territorio de la UE. Bruselas: Comisión Europea.

Comisión Europea (2007). Agenda para un turismo europeo sostenible y competitivo. Recuperado de https:// eur-lex.europa.eu/legal-content/ES/ALL/?uri=CELEX\%3A52007DC0621

Consejo de Europa (CE) (2000). Convenio Europeo del Paisaje. Florencia: Unión Europea.

Crouch, D. (2006). Tourism, consumption and rurality. In P. Clocke, T. Marsden, P., \& Mooney (Eds.), The Handbook of Rural Studies (pp. 355-364). https://doi.org/10.4135/9781848608016.n25

Cruz, L. (Ed.) (2015). 100 Paisajes Culturales en España. Madrid: Ministerio de Educación, Cultura y Deporte del Gobierno de España.

Elías, L.V. (Ed.) (2016). Atlas del cultivo tradicional del viñedo y de sus paisajes singulares. Madrid: Ministerio de Agricultura, Pesca y Alimentación.

Fernández, V., \& Silva, R. (2015). Criterios para la identificación y selección de paisajes españoles susceptibles de ser incluidos en la Lista del Patrimonio Mundial de Unesco. Boletín de la Asociación de Geógrafos Españoles, (68), 253-278. https://doi.org/10.21138/bage.1861

Fish, R., Church, A., \& Winter, M. (2016). Conceptualising cultural ecosystem services: a novel framework for research and critical engagement. Ecosystem Services, (21), 208-217. https://doi.org/10.1016/j. ecoser.2016.09.002

Getz, D., \& Brown, G. (2006). Critical success factors for wine tourism regions: a demand analysis. Tourism management, (27), 146-158. http://doi.org/10.1016/j.tourman.2004.08.002

Gravari-Barbas, M. (2014). Winescapes. Tourisme et artialisation, entre lo global et le local. Vinho, Patrimonio, Turismo e Desenvolvimento: Convergencias ao debate e ao desenvolvimiento das regioes vinícolas munidais. $N^{o}$ Spécial CULTUR, Revista de Cultura e Turismo, 8(3), 238-255. 
Hall, C.M., Longo, A.M., Mitchell, R., \& Johnson, G. (2000) Wine tourism in New Zealand. En C.M. Hall, L. Sharples, B. Cambourne and N. Macionis (Eds.), Wine Tourism Around the World: Development, management and markets (pp. 150-176). https://doi.org/10.4324/9780080521145-8

Hall, C. M., \& Mitchell, R. (2002). The touristic terroir of New Zealand wine: the importance of region in the wine tourism experience. In Montanari, A. (Ed.), Food and environment: geographies of taste (pp. 69-91). Roma: Societa Geografica Italiana.

Haines-Young, R. \& Potschin, M. B. (2017). Common International Classification of Ecosystem Services (CICES) V5.1 and guidance on the application of the revised structure. Nottingham: CICES. Recuperado de http://www.cices.eu

Hernández, S., González, A., \& Ramón, A. (2017). El paisaje vinícola como recurso turístico y territorial en Lanzarote (Canarias, España). Ería, (3), 321-334.

Instituto del Patrimonio Cultural de España (IPCE) (2015). Plan Nacional de Paisaje Cultural. Madrid, Ministerio de Educación, Cultura y Deporte. Recuperado de http://www.mecd.gob.es/planesnacionales/dms/microsites/cultura/patrimonio/planes-nacionales/textos-planes-nacionales/05maquetado-paisaje-cultural.pdf

Kayser, B. (1990). La renaissance rurale: sociologie des campagnes du monde occidental. Paris: Armand Colin.

Lorenzini, E. (2010). Origin labelled products, territorial marks and their contribution to rural development. Evidence from Italy and France. In Società Italiana di Economía Publica, (Working paper, 19 p.). University of Pavia (Italy).

Mata, R. (2016). El Plan Nacional de Paisaje Cultural. Una iniciativa para el conocimiento, la cooperación y la salvaguarda de paisajes de alto interés cultural. En FUNDICOT (Ed.), Nuevos tiempos, nuevos objetivos (pp. 545-560). Fuerteventura: Gobierno de Canarias y Otros.

Millennium Ecosystem Assessment (MEA) (2005). Ecosystems and Human Well-being: Synthesis. Washington DC: Island Press.

Ministerio de la Presidencia (Ed.) (2007). Estrategia Española de Desarrollo Sostenible. Madrid: Ministerio de la Presidencia.

Molinero, F. (2016). Los paisajes patrimoniales en el desarrollo rural. En F. Leco (Ed.), Territorio y Desarrollo Rural: aportaciones desde el ámbito investigador (pp. 15-38). Cáceres: Junta de Extremadura y Otros.

Molinero, F., Tort, J., Mata, R., Silva, R., García, J. L., Porcal, M. C., \& Ruiz, E. (Coords.) (2018). Paisajes patrimoniales de España. 3 Tomos. Madrid: Ministerio de Agricultura, Pesca y Alimentación, Ministerio para la Transición Ecológica y Ediciones UAM.

Organización de Naciones Unidas (2012). El Futuro que queremos. Recuperado de https://rio20.un.org/ sites/rio20.un.org/files/a-conf.216-1-1_spanish.pdf.pdf

Organización Mundial del Turismo (OMT) (1994). Actualización de las Recomendaciones sobre estadísticas de turismo OMT-ONU. Serie M, (83). Recuperado de https://unstats.un.org/unsd/statcom/doc00/ m83note-s.pdf

Organización Mundial del Turismo (OMT) (1999). Código Ético Mundial para el Turismo. Recuperado de http://ethics.unwto.org/es/content/codigo-etico-mundial-para-el-turismo

Organización Mundial del Turismo (OMT) (2017a). Año Internacional del Turismo Sostenible para el Desarrollo. Recuperado de https://media.unwto.org/es/press-release/2017-01-16/2017-anointernacional-del-turismo-sostenible-para-el-desarrollo

Organización Mundial del Turismo (OMT) (2017b). Travel, Enjoy, Respect. Recuperado de https://media. unwto.org/es/press-release/2017-08-22/la-omt-lleva-cabo-la-campana-travelenjoyrespect-0

Organización Mundial del Turismo (OMT) (2019). Panorama OMT del Turismo Internacional. Edición 2018, 2019. Madrid: OMT.

Organización Mundial del Turismo (OMT) (2020). Sustainable Development of Tourism. Recuperado de https://www.unwto.org/es/desarrollo-sostenible 
Panadero, M. (2010). Geografía humana y sostenibilidad. Hitos y perspectivas. En F. Pillet, M.C. Cañizares, \& Ruíz Pulpón, A.R. (Eds.), Territorio, Paisaje y Sostenibilidad. Un mundo cambiante (pp. 49-86). Barcelona: Ediciones del Serbal.

Pillet, F. (2008). Espacio y ciencia del territorio. Proceso y relación global-local. Madrid: Biblioteca Nueva.

Plieninger, T., Dijks, S., Oteros-Rozas, E., \& Bieling, C. (2013). Assessing, mapping, and quantifying cultural ecosystem services at community level. Land Use Policy, (33), 118-129. https://doi. org/10.1016/j.landusepol.2012.12.013

Porcal, M.C. (2019). Búsqueda de especificidades en el carácter de los paisajes del viñedo e identificación de sus procesos de patrimonialización. La Rioja Alavesa como laboratorio. Cuadernos Geográficos, 58(2), 215-239. http://dx.doi.org/10.30827/cuadgeo.v58i2.7390

Rosenberg, R.S., \& Walsh, R.G. (1997). Nonmarket Value of Western Valley Ranchland Using Contingent Valuation. Journal of Agricultural and Resource Economics, 22(2), 296-309. Recuperado de https://www. jstor.org/stable/40986949?seq=1

Rubio, P. (2010). El Patrimonio Rural. En F. Leco, A. Pérez, \& B. Mateos (Eds.), Geografía y Desarrollo Rural. Territorio, Paisaje y Patrimonio (pp. 111-177). Cáceres: Universidad de Extremadura.

Ruiz Pulpón, A.R. (2013). Producción agroalimentaria de calidad y postproductivismo agrario: el caso de los vinos de pago en Castilla-La Mancha, Anales de Geografía de la Universidad Complutense, 33(2), 137-154. https://doi.org/10.5209/rev_AGUC.2013.v33.n2.43007

Ruiz Pulpón, A.R., \& Cañizares, M.C. (2017). Paisaje cultural del viñedo e identidad territorial en Castilla-La Mancha. En Allende, F. et al. (Eds). Naturaleza, territorio y ciudad en un mundo global (pp. 2225-2234). Madrid: Asociación de Geógrafos Españoles y Universidad Autónoma de Madrid.

Ruiz Pulpón, A.R., \& Plaza Tabasco, J. (2015). Distintivos de calidad agroalimentaria en Castilla-La Mancha (España). Influencia de la escala en la gobernanza territorial. Desenvolvimento Regional $\mathrm{em}$ debate, 5(2), 48-70. https://doi.org/10.24302/drd.v5i2.991

Ruiz Urrestarazu, E. (2001). Patrimonio rural y políticas europeas. Lurralde Investigación y espacio, (24), 305-314.

Short, B. (2006). Idyllic ruralities. In P. Clocke, T Marsden, \& P. Mooney (Eds.), The Handbook of Rural Studies (pp. 133-148). https://doi.org/10.4135/9781848608016.n9

Sanz, C. (2012). Paisaje y Patrimonio Natural y Cultural: historia y retos actuales. Nimbus, (29-30), 687-700.

Silva, R. (2008). Hacia una valoración patrimonial de la agricultura. Scripta Nova. Revista Electrónica de Geografía y Ciencias Sociales, XII(275). Recuperado de http://www.ub.edu/geocrit/sn/sn-275.htm

Silva, R. (2009). Agricultura, Paisaje y Patrimonio Territorial. Los paisajes de la agricultura vistos como patrimonio. Boletín de la Asociación de Geógrafos Españoles, (4), 309-334.

Silva, R., \& Fernández, V. (2017a). The limitess concept: the new heritage paradigm and its relation to space. En F. Manero, \& J.L. García Cuesta (Eds.), Territorial heritage and spatial planning. A geographical perspective (pp. 57-84). Pamplona: Thomson Reuters Aranzadi.

Silva, R., \& Fernández, V. (2017b). El nuevo paradigma del patrimonio y su consideración con los paisajes: conceptos, métodos y prospectivas. Documents d'Anàlisi Geogràfica, (63/1), 129-151. https:// doi.org/10.5565/rev/dag.344

Tengberg, A., Fredholm, S., Eliasson, I., Knez, I., Saltzman, K., \& Wetterberg, O. (2012). Cultural ecosystem services provided by landscapes: Assessment of heritage values and identity. Ecosystem Services, (2), 14-26. https://doi.org/10.1016/j.ecoser.2012.07.006

Tregear, A., Arfini, F., Belletti, G., \& Marescotti, A. (2007). Regional foods and rural development: The role of product qualification. Journal of Rural Studies, (23), 12-22. https://doi.org/10.1016/j. jrurstud.2006.09.010

Vera, J.F., Palomeque, F.L., Gómez, M.J.M., \& Clavé, S.A. (2013). Análisis territorial del turismo y planificación de destinos turísticos. Valencia: Tirant Humanidades

Winkler, A.J., \& Nicholas, K.A. (2016). More than wine: Cultural ecosystem services in vineyard landscapes in England and California. Ecological Economics, (124), 86-98. https://doi.org/10.1016/j. ecolecon.2016.01.013 